\title{
PREVALENCIA DE ANTICUERPOS CONTRA EL VIRUS DE LA ENFERMEDAD DE NEWCASTLE EN Gallus gallus DE LIMA. ESTUDIO DE CASO-CONTROL
}

\section{Prevalence of Newcastle Disease Virus Antibodies in Gallus gallus in Lima. Case Control Study}

\author{
Rocky Ferrer M. ${ }^{1}$, Eliana Icochea D. ${ }^{1,2}$, Arturo Salas S. ${ }^{3}$ y Mónica Alba Ch. ${ }^{1}$
}

\section{ResUMen}

\begin{abstract}
Se analizaron los resultados de la prueba de inhibición de la hemoaglutinación (HI) para la enfermedad de Newcastle (ENC) realizada en 390 sueros de aves de crianza industrial (pollos de carne, ponedoras comerciales y reproductoras) y 343 sueros de aves de crianza no tecnificada (aves de riña y crianza casera), colectados por el Servicio Nacional de Sanidad Agraria (SENASA) durante un monitoreo serológico realizado en el 2001. Se diseñó una tabla de interpretación de resultados de la prueba HI para la ENC teniendo en cuenta el número y tipo de vacunas aplicadas a cada ave. Se obtuvo una prevalencia de aves con títulos de anticuerpos compatibles a un desafío con el virus de la ENC de $1.8 \pm$ $1.3 \%$ en la crianza industrial y de $9.9 \pm 3.2 \%$ en la crianza no tecnificada. El análisis de regresión logística mostró que la crianza no tecnificada representa un factor de riesgo $(\mathrm{p}<0.0001)$ asociado a encontrar un título de anticuerpos de la prueba HI compatible con un reto de campo con el virus de la ENC, teniendo la crianza no tecnificada un Odds Ratio de 6.02 (I.C. 2.6-13.8 respecto a la crianza industrial). Los resultados obtenidos indican que el virus de la ENC se encuentra endémico en el departamento de Lima, teniendo como principales hospederos a las aves de crianza no tecnificada.
\end{abstract}

Palabras clave: enfermedad de Newcastle, Lima, prevalencia, odds ratio

\section{Abstract}

The present research work evaluated the results of 390 serum samples collected to birds reared in commercial farms (broilers, egg-laying hens, and breeders) and 343 serum samples collected to birds reared in non-technical farms (backyard and fighting birds) that were analyzed by the hemoagglutination inhibition (HI) test for the Newcastle disease (ND). Samples were collected by the SENASA (national authority for animal health) as part of a national serological survey in the second semester of year 2001. An interpretation table for the results of the HI test was designed by a team of experts taking into consideration the number and type of vaccines against ND used. The prevalence rate of

\footnotetext{
${ }^{1}$ Laboratorio de Patología Aviar, Facultad de Medicina Veterinaria, Universidad Nacional Mayor de San Marcos, Lima

${ }^{2}$ E-mail: eliana.icochea@gmail.com

${ }^{3}$ Laboratorio Intervet
} 
birds with antibody titers compatible to a Newcastle virus challenge was $1.8 \pm 1.3 \%$ in birds from commercial farms and $9.9 \pm 3.2 \%$ in birds from non-technical farms. The logistic regression analysis showed that birds from non-technical farms represent a risk factor $(\mathrm{p}<0.0001)$ in obtaining antibody titers compatible to a Newcastle virus challenge (Odds Ratio was 6.02 with confidence interval of 2.6-13.8) as compared to birds from commercial farms. The results showed that the ND virus is endemic in the area of Lima, especially in birds of non-technical farms.

Key words: Newcastle disease, Lima, prevalence, odds ratio

\section{INTRODUCCIÓN}

La enfermedad de Newcastle (ENC) es producida por un virus que pertenece al género Avulavirus, de la familia Paramyxoviridae (Mayo, 2002). Es una enfermedad altamente contagiosa, de curso fatal y de gran impacto económico, ya que representa un factor limitante para la exportación de productos avicolas, dados los actuales esquemas de ordenamiento del comercio internacional. La enfermedad fue reportada por primera vez en el país a mediados del siglo pasado (Philipps et al., 1951). La enfermedad dejó de ser un problema serio a mediados de los 90, pero en los últimos años se ha observado un incremento de aislamientos virales, principalmente a partir de brotes ocurridos en aves de riña.

Para lograr la erradicación de las formas velogénicas de la ENC se requiere identificar y eliminar las fuentes de contaminación. Los estudios de detección de anticuerpos llevados a cabo en aves silvestres de las órdenes Columbiformes, Paseriformes y Psitaciformes en el departamento de Lima han dado resultados negativos (Chang, 1998; Carrión, 2000; Shimabukuro, 2000); sin embargo, en el país no existen trabajos previos de seroprevalencia en aves de crianza industrial, de riña o casera, aun cuando estos dos últimos tipos de crianza han sido responsabilizados de mantener la enfermedad endémica en países donde su crianza es masiva, así como de ocasionar brotes en las explotaciones avícolas industriales.
El presente estudio analiza e interpreta los resultados de los títulos de anticuerpos obtenidos mediante la prueba de inhibición de la hemoaglutinación, para determinar la prevalencia de aves con títulos indicativos de reto de campo con el virus de la ENC, tanto en la crianza industrial como en la no tecnificada de aves domésticas (Gallus gallus). Así mismo, se hizo un estudio de caso-control analizado mediante una regresión logística para determinar el nivel de contribución del tipo de crianza en el contacto del ave con el virus.

\section{Materiales y Métodos}

\section{Recolección de Datos}

En el presente trabajo se utilizaron las fichas clínicas y resultados de las pruebas de inhibición de la hemoaglutinación para detectar anticuerpos contra el virus de la ENC de un monitoreo que formó parte de la vigilancia epidemiológica de la ENC llevado a cabo en el departamento de Lima por el Servicio Nacional de Sanidad Agraria durante el año 2001 en aves de crianza industrial (390 sueros de pollos de carne, ponedoras comerciales y reproductoras) y de crianza no tecnificada (343 sueros de aves de riña y de crianza casera). Los sueros de las aves se analizaron mediante la técnica de inhibición de la hemoaglutinación (HI) descrita por Alexander (1989), usando un titulo de antígeno de 8 unidades hemoaglutinantes (UH) para las muestras de aves de crianza industrial y de $4 \mathrm{UH}$ para las aves de crianza no tecnificada. 
Cuadro 1. Tabla de interpretación ${ }^{1}$ de anticuerpos compatibles a un desafío de campo utilizando la prueba de hemoaglutinación en aves con o sin vacunación contra la enfermedad de Newcastle

\begin{tabular}{lcl}
\hline Programa de vacunación & $\begin{array}{c}\text { Títulos } \\
\text { individuales }\end{array}$ & Hemoaglutinación \\
\hline Ninguno & $1: 2$ & Negativo \\
& $1: 4$ & Sospechoso \\
& $? 1: 8$ & Positivo \\
1 vacuna con virus activo & $? 1: 8$ & Negativo \\
& $1: 16$ & Sospechoso \\
& $? 1: 32$ & Positivo \\
2 a 3 vacunas con virus activo & $? 1: 16$ & Negativo \\
& $1: 32$ & Sospechoso \\
& $? 1: 64$ & Positivo \\
4 a 5 vacunas con virus activo & $? 1: 32$ & Negativo \\
& $1: 64$ & Sospechoso \\
1 vacuna con virus activo + & $? 1: 128$ & Positivo \\
1 vacuna con virus inactivado & $? 1: 16$ & Negativo \\
& $1: 32$ & Sospechoso \\
1 a 2 vacunas con virus activo + & $? 1: 64$ & Positivo \\
1 a 3 vacunas con virus inactivado & $? 1: 32$ & Negativo \\
& $1: 64$ & Sospechoso \\
3 a 5 vacunas con virus activo & $? 1: 128$ & Positivo \\
1 a 2 vacunas con virus inactivado & $? 1: 128$ & Negativo \\
\hline
\end{tabular}

\footnotetext{
${ }^{1}$ Panel de expertos conformado por la Dra. Eliana Icochea D’Arrigo y la Dra. Mónica Alba Chincha de la Facultad de Medicina Veterinaria, UNMSM, el Dr. Arturo Salas Serrano de Intervet, Lima, y la Dra. Sonia Cortez de Jäckel del Laboratorio de Microbiología y Serología Clínica de Aves, Delbrück, Alemania.
}

\section{Interpretación de Resultados}

Una limitante para el análisis e interpretación de los resultados de la prueba diagnóstica de HI fue la ausencia de un patrón de interpretación. Por tal motivo, con la colaboración de cuatro profesionales con amplia experiencia en el diagnóstico de laboratorio, se diseñó una tabla de interpretación de títulos de anticuerpos compatibles a un desafío de campo con el virus de la ENC, clasificándolos en negativos, sospechosos o po- sitivos (Cuadro 1). Se tuvo en cuenta la ocurrencia de vacunación, así como el número y tipo de vacunas (virus vivo y/o inactivado).

\section{Análisis de Datos}

Se calculó la prevalencia de aves con niveles de anticuerpos compatible s con un desafío con el virus de la ENC (sospechosas y positivas), tanto en aves de crianza industrial como no tecnificada, mediante la formula descrita por Ahlbom y Norell (1990) 
con su respectivo intervalo de confianza del 95\% (Armitage y Berry, 1987).

Se diseñó un estudio de caso control, para calcular mediante una regresión logística usando el programa estadístico STATA ${ }^{\circledR}$, la asociación entre el tipo de crianza y la presencia de niveles de anticuerpos contra el virus de la ENC que fueran indicativos de reto de campo; utilizando así mismo, el Odds Ratio, que expresa el riesgo de encontrar un ave positiva en el grupo expuesto (crianza no tecnificada) que en el no expuesto (crianza industrial).

\section{Resultados}

Los títulos de anticuerpos de los sueros de las aves de crianza industrial y no tecnificada analizados por HI, de acuerdo a la tabla de interpretación elaborada para este estudio (Cuadro 1), se encuentran en los cuadros 2 y 3 . La prevalencia de aves con niveles de anticuerpos compatibles a un desafío con el virus de la ENC fue de $1.8 \pm 1.3 \%$ en aves de crianza industrial y de $9.9 \pm 3.2 \%$ en aves de crianza no tecnificada.

Cuadro 2. Títulos de anticuerpos contra el virus de la enfermedad de Newcastle por la prueba de hematoaglutinación en aves de crianza industrial en el departamento de Lima (2001)

\begin{tabular}{|c|c|c|c|c|c|c|c|c|c|c|c|}
\hline \multirow{2}{*}{$\begin{array}{l}\text { Programa de } \\
\text { vacunación }\end{array}$} & \multirow{2}{*}{$\begin{array}{l}\text { Tipo de } \\
\text { explotación }\end{array}$} & \multirow{2}{*}{$\mathrm{ST}^{1}$} & \multicolumn{8}{|c|}{ Título de anticuerpos } & \multirow{2}{*}{ Total } \\
\hline & & & $1: 2$ & $1: 4$ & $1: 8$ & $1: 16$ & $1: 32$ & $1: 64$ & $1: 128$ & $1: 256$ & \\
\hline $\begin{array}{l}1 \text { con virus } \\
\text { activo }\end{array}$ & $\begin{array}{l}\text { Pollo de } \\
\text { carne }\end{array}$ & 11 & 3 & 6 & 7 & $2^{*}$ & 0 & $1 * *$ & 0 & 0 & 30 \\
\hline \multirow{2}{*}{$\begin{array}{l}2-3 \text { con } \\
\text { virus activo }\end{array}$} & $\begin{array}{l}\text { Pollo de } \\
\text { carne }\end{array}$ & 152 & 32 & 46 & 23 & 14 & $1^{*}$ & $1 * *$ & $1 * *$ & 0 & 270 \\
\hline & $\begin{array}{l}\text { Ponedora } \\
\text { comercial }\end{array}$ & 2 & 2 & 4 & 1 & 1 & 0 & 0 & 0 & 0 & 10 \\
\hline $\begin{array}{l}4-5 \text { con } \\
\text { virus activo }\end{array}$ & $\begin{array}{l}\text { Madre de } \\
\text { carne }\end{array}$ & 3 & 2 & 4 & 5 & 1 & 5 & 0 & 0 & 0 & 20 \\
\hline \multirow{3}{*}{$\begin{array}{l}3-5 \text { con } \\
\text { virus activo } \\
+1-2 \text { con } \\
\text { virus inacti- } \\
\text { vado }\end{array}$} & $\begin{array}{l}\text { Ponedora } \\
\text { comercial }\end{array}$ & 0 & 1 & 1 & 16 & 12 & 9 & 1 & 0 & 0 & 40 \\
\hline & $\begin{array}{l}\text { Madre de } \\
\text { carne }\end{array}$ & 3 & 2 & 5 & 0 & 0 & 0 & 0 & 0 & 0 & 10 \\
\hline & $\begin{array}{l}\text { Madre de } \\
\text { postura }\end{array}$ & 0 & 0 & 0 & 1 & 0 & 5 & 2 & 1 & $1 *$ & 10 \\
\hline
\end{tabular}

${ }^{1}$ Sin t ítulo

* Sospecha de desafío

** Positivo a un desafío 
Cuadro 3. Títulos de anticuerpos contra el virus de la enfermedad de Newcastle por la prueba de hematoaglutinación en aves de crianza no tecnificada en el departamento de Lima (2001)

\begin{tabular}{|c|c|c|c|c|c|c|c|}
\hline \multirow{2}{*}{ Programa de vacunación } & \multirow{2}{*}{$\begin{array}{l}\text { Tipo de } \\
\text { explotación }\end{array}$} & \multirow{2}{*}{$\mathrm{ST}^{1}$} & \multicolumn{4}{|c|}{ Título de anticuerpos } & \multirow{2}{*}{$\begin{array}{c}\text { Total de } \\
\text { sueros }\end{array}$} \\
\hline & & & $1: 2$ & $1: 4$ & $1: 8$ & $1: 16$ & \\
\hline \multirow[t]{2}{*}{ Sin vacunación } & Crianza casera & 123 & 11 & $21 *$ & $6^{* *}$ & $1^{* *}$ & 162 \\
\hline & Ave de riña & 68 & 2 & $2 *$ & $3 * *$ & $1 * *$ & 76 \\
\hline \multirow[t]{2}{*}{1 vacuna con virus activo } & Crianza casera & 10 & 0 & 0 & 0 & 0 & 10 \\
\hline & Ave de riña & 55 & 0 & 0 & 0 & 0 & 55 \\
\hline \multirow{2}{*}{$\begin{array}{l}\text { 2-3 vacunas con virus } \\
\text { activo }\end{array}$} & Crianza casera & 10 & 0 & 0 & 0 & 0 & 10 \\
\hline & Ave de riña & 24 & 1 & 1 & 3 & 1 & 30 \\
\hline
\end{tabular}

${ }^{1}$ Sin título

* Sospecha de desafío

** Positivo a un desafío

El análisis de regresión logística indicó que la crianza no tecnificada representa un factor de riesgo $(\mathrm{p}<0.0001)$ asociado a encontrar un título de anticuerpos compatible con un reto de campo con el virus de la ENC. La crianza no tecnificada tuvo un Odds Ratio de 6.02 (2.63- 13.77 I.C.) respecto a la crianza industrial.

En la crianza no tecnificada (Cuadro 3), todas las muestras con resultados compatibles a un reto viral pertenecieron a aves que no habían sido vacunadas (aves de crianza casera: $28 / 182,15.4 \%$ y las aves de riña: $6 /$ $155,3.7 \%)$.

\section{Discusión}

Los resultados del estudio y los reportes de brotes de la enfermedad indican que el virus de la ENC es endémico en el departamento de Lima, y con mayor prevalencia en las aves de crianza no tecnificada. La baja prevalencia en aves de crianza industrial, especialmente en pollos de carne, se debería probablemente a fallas en el sistema de bioseguridad.
El análisis de la casuística del Laboratorio de Patología Aviar de la Facultad de Medicina Veterinaria de la Universidad Nacional Mayor de San Marcos indica que la ENC se encuentra entre las 10 enfermedades con mayor frecuencia de diagnóstico (Cortéz, 1970; Inga, 1991), y los resultados del presente estudio demuestran que el virus persiste en el tiempo como un agente que afecta a las explotaciones avícolas en el Perú.

El virus de Newcastle se mantiene endémico mientras encuentre aves susceptibles (Martín, 1991). En la crianza no tecnificada, las aves que no se han infectado y aquellas que se incorporan en el criadero (aves no vacunadas o insuficientemente protegidas) se consideran aves susceptibles. Así, la presencia de aves sanas a quienes las aves infectadas tienen la posibilidad de infectar, genera un ciclo de diseminación viral continuo dentro de la crianza no tecnificada; por el contrario, las aves de crianza industrial tienen programas de vacunación que incluyen a toda la población de la granja, lo que detiene el ciclo de diseminación viral al no haber aves susceptibles. En aves de traspatio se pueden encontrar aves con y sin la infección (Johnston 
y Cumming, 1991). Es posible que ocurra en este tipo de crianza un lento nivel de transmisión entre aves infectadas y sanas debido a la baja densidad poblacional, a la agrupación natural de aves por edades y a la alimentación a campo abierto.

En la zona de Lima se utilizan vacunas a virus activo en toda la población de aves de crianza industrial y parcialmente en la crianza no tecnificada. La presencia de estas cepas lentogénicas podría estar creando ciclos de infección en aves de crianza no tecnificada e incrementando la inmunidad en las aves expuestas. Esta inmunidad es muy variable e insuficiente para resistir el desafío con una cepa velogénica (Samuel y Spradbrow, 1989), pero la presencia de estas cepas de baja virulencia circulando dentro de las poblaciones avícolas de crianza no tecnificada es un factor que altera la severidad de los brotes de la ENC en su forma clásica (con mortalidades cercanas al 100\%).

Los resultados del estudio corroboran las observaciones de otros estudios que indican que las aves de traspatio son las que se encuentran más afectadas por la ENC. Así, Alexander (1996) reporta que el total de los 133 brotes ocurridos en 1993 en Alemania fueron en crianzas de traspatio; en tanto que 52 de los 68 brotes durante el periodo 1992/ 1994 en Bélgica y el 65\% de los brotes reportados en 1994 en Portugal se presentaron en aves de traspatio.

Los principales factores que estarían contribuyendo a que la crianza no tecnificada tenga un mayor riesgo de contacto con el virus de la ENC serían: a) un gran porcentaje de aves no están vacunadas o tienen insuficiente protección vacunal, b) el bajo nivel de bioseguridad, c) la crianza de aves de edades múltiples, y 4) la convivencia, en algunos casos, con especies de aves menos susceptibles que pueden infectarse y no mostrar sintomatología clínica grave como son los pavos, codornices y aves silvestres, pero que sí pueden excretar y diseminar el virus.
Al evaluar los grupos de aves que conformaron la crianza no tecnificada se observó una relación inversa entre el porcentaje de casos compatibles a un desafío viral y la cobertura de vacunación del grupo; así, las aves de crianza casera tuvieron el mayor porcentaje de casos indicativos de un desafío viral $(15.4 \%)$ y una menor cobertura vacunal $(11.0 \%, 20$ aves vacunadas de 182 muestreadas), en tanto que las aves de riña tuvieron un menor porcentaje de casos que evidenciaban reto viral $(3.7 \%)$ y una mayor cobertura vacunal $(52.8 \%, 85$ aves vacunadas de 161 aves muestreadas).

Aunque las aves de riña tuvieron el menor porcentaje de casos con niveles de anticuerpos compatibles con un desafío viral en relación a las aves de crianza casera, se puede considerar que las aves de riña representan un mayor riesgo para la diseminación de la enfermedad por su constante movilización, el contacto con otras aves en coliseos, la práctica de intercambios entre criadores y la creencia popular que la vacunación disminuye el vigor de sus aves para la pelea, induciendo a que los criadores dejen de vacunar a sus aves.

En la crianza de pollos de carne se encontró una proporción de 6/200 aves infectadas con títulos del virus de ENC correspondientes a desafío de campo, mientras que en las reproductoras de postura se observó una proporción de 1/10 aves afectadas. Dichos resultados no permiten determinar el grupo de mayor riesgo de infección; sin embargo, se puede concluir que ambos grupos evidencian la exposición a un desafío de campo a pesar de los programas vacunales correspondientes a cada especie.

El mayor número de aves positivas en pollos de carne obtenidas en el presente estudio, estaría asociado a deficientes condiciones de bioseguridad (falta de concientización del personal, programas de vacunación poco intensivos e interacción con agentes inmunosupresivos), en comparación con los altos niveles de bioseguridad en los 
planteles de reproductoras. Sin embargo, la comparación misma es relativa al no tener muestras homogéneas para determinar con precisión y confiabilidad dicha asociación.

Los resultados obtenidos en el presente trabajo indican que el virus de la enfermedad de Newcastle tiene grandes posibilidades de permanecer en las explotaciones avícolas. Según el III Censo Nacional Agropecuario (INEI, 1994), el $41.5 \%$ de las unidades agropecuarias del departamento de Lima crían aves domésticas, siendo las aves de crianza no tecnificada una fuente de mantenimiento y difusión del virus con gran riesgo para la crianza industrial. Aun cuando la vacunación es total en la crianza industrial, hay muchos factores que pueden conducir a una falla en los programas de vacunación y facilitar a la presentación de brotes de la enfermedad; entre ellos se puede considerar el inadecuado manejo de las vacunas, el uso de vacunas mal conservadas con fecha de expiración vencida, aves que se vacunan bajo condiciones de estrés, insuficiente vacunación y aves sometidas a la presencia de agentes inmunosupresores (virus de la enfermedad de Gumboro, virus de la anemia del pollo, virus de la enfermedad de Marek y algunas micotoxinas).

\section{Conclusiones}

? La prevalencia de aves con niveles de anticuerpos indicativos de reto de campo con el virus de la ENC fue de $1.8 \pm$ $1.3 \%$ en la crianza industrial y de $9.9 \pm$ $3.2 \%$ en aves de crianza no tecnificada.

? En aves de crianza no tecnificada, el $15.4 \%$ de las aves de crianza casera y el 3.7\% de las aves de riña tuvieron títulos de anticuerpos que evidenciaron un reto viral.

? La crianza no tecnificada es un factor de riesgo $(p<0.0001)$ asociado a un reto de campo con el virus de la ENC.
? El virus de la enfermedad de Newcastle se encuentra endémico en el departamento de Lima, siendo las aves de crianza no tecnificada las principales hospederas del virus.

\section{Literatura Citada}

1. Ahlbom A, Norell S. 1990. Introduction to modern epidemiology. $2^{\text {nd }} \mathrm{ed}$. Massachusetts: Epidemiology Resources.

2. Alexander D. 1996. Enfermedad de Newcastle: perspectiva europea. Industria Avicola 42: 22-24.

3. Alexander D. 1989. Newcastle disease. In: A laboratory manual for the isolation and identification of the avian pathogens. $3^{d}$ ed. Iowa: Kendall/Hunt Publishing Co. p 156-163.

4. Armitage P, Berry G. 1987. Statistical methods in medical research. $2^{\text {nd }}$ ed. Oxford: Blackwell Scientific Publications.

5. Carrión A. 2000. Prevalencia de anticuerpos contra el virus de la enfermedad de Newcastle en aves silvestres del orden Columbiforme en Baños de Boza, distrito de Okayama, provincia de Huaral. Tesis de Médico Veterinario. Lima: Facultad de Medicina Veterinaria, Univ. Nacional Mayor de San Marcos. 33 p.

6. Chang E. 1998. Detección de la prevalencia de anticuerpos contra el virus de la enfermedad de Newcastle en aves silvestres Paseriformes y Columbiformes en la provincia de Chancay. Tesis de Médico Veterinario. Lima: Facultad de Medicina Veterinaria, Univ. Nacional Mayor de San Marcos. 33 p.

7. Cortez S. 1970. Estudio retrospectivo de las principales enfermedades diagnosticadas en el Laboratorio de Patología Aviar durante 1956-1969. Tesis de Bachiller. Lima: Facultad de Medicina Veterinaria, Univ. Nacional Mayor de San Marcos. $51 \mathrm{p}$. 
8. [INEI] Instituto Nacional de Estadística e Informática. 1994. III Censo Nacional Agropecuario. Lima: INEI. p 2484-2489.

9. Inga E. 1991. Análisis estadístico retrospectivo de las principales enfermedades diagnosticadas en el Laboratorio de Patología Aviar en los últimos diez años. Tesis de Bachiller. Lima: Facultad de Medicina Veterinaria, Univ. Nacional Mayor de San Marcos. 50 p.

10. Johnston J, Cumming R. 1991. Control of Newcastle disease in village chickens with oral V4 vaccine. Camberra: ACIAR Working Paper $\mathrm{N}^{\circ} 35$.

11. Martin P. 1991. The epidemiology of Newcastle disease in village chickens. In: International Seminar Newcastle disease in village chicken-control with termostable oral vacines. Kuala Lumpur:
Asia Pacific University College of Technology \& Innovation. Abstract.

12. Mayo M. 2002. Virus taxonomy Houston 2002. Arch Virol 147: 1071-1076.

13. Philipps L, Navaes O, Fernández L. 1951. La neumoencefalitis aviar en el Perú. Rev Inst Nac Biol Animal 2: 31-51.

14. Samuel J, Spradbrow P. 1989. Persistence of the V4 strain of Newcastle disease virus in an openrange flock of chickens. Vet Rec 124: 193-196.

15. Shimabukuro I. 2000. Determinación de anticuerpos contra el virus de la enfermedad de Newcastle en Psitacidas en cautiverio en el Parque de las Leyendas. Tesis de Médico Veterinario. Lima: Facultad de Medicina Veterinaria, Univ. Nacional Mayor de San Marcos. 26 p. 